\title{
М.К. Тимофеева
}

\section{ТЕОРИЯ РИТОРИЧЕСКОЙ СТРУКТУРЫ КАК ИНСТРУМЕНТ АНАЛИЗА СТИХОТВОРНЫХ ТЕКСТОВ ${ }^{1}$}

\begin{abstract}
Представлен результат адаптаџии и применения теории риторической структуры У. Манна и С. Томпсон к стихотворным текстам. Предложены и апробированы принципы сегментации текста и идентификации отночений, ориентированные на реконструкцию гетерогенного познавательного процесса, воплощённого в тексте. Проведён сравнительный анализ схем, построенных для следуюших групп текстов: лирическихстихотворений трёх периодов творчества А.К. Толстого, его прозаических текстов и переводов.

Ключевые слова: риторические отношения, реляционные пропозиции, структура познавательного процесса, стихотворные тексты, связность текста, А.К. Толстой.
\end{abstract}

\section{Введение}

Данная работа выполнена в рамках реализации проекта по многоуровневому анализу текстов русской классической поэзии XIX - начала XX в. Проект нацелен на разработку инструментария для анализа (в частности, сравнительного) различных аспектов текстов, алгоритмизацию и автоматизацию ряда процедур обработки текстов, создание на этой основе различного рода справочно-аналитических ресурсов: словарей, метрических справочников, конкордансов. Изучаемые в рамках проекта аспекты текстов включают как специфические для поэзии метроритмические характеристики, так и составляющие традиционных языковых уровней (фонетического, лексико-семантического, прагматического).

Статья представляет результаты изучения прагматического уровня. Цель исследования состояла в применении теории риторической структуры (ТPC, Rhetorical structure theory) [1] к стихотворным текстам и предусматривала следующие этапы реализации: 1) разработка процедуры применения ТРС к стихотворным текстам; 2) построение схем ТРС для выбранного множества текстов; 3) анализ построенных схем. Необходимость первого этапа обусловлена тем, что опыт использования ТРС для анализа стихотворных текстов отсутствует. Материалом исследования послужили лирические стихотворения А.К. Толстого, а также фрагменты написанных им прозаических текстов, письма, переводы стихотворений других авторов. Общий объём проанализированных текстов составил 5985 словоупо-

\footnotetext{
${ }^{1}$ Работа выполнена при поддержке Российского научного фонда, проект № 19-1800466 «Разработка и реализация информационной системы многоуровневого исследования стихотворных текстов».
} 
треблений. Для построения структур ТРС использовался инструмент разметки RSTTool [2] (http://www.wagsoft.com/RSTTool/).

Исследование проведено в рамках когнитивного подхода к ТРС [3. C. 30-31], нацеленного на изучение когнитивных (познавательных) процессов, происходящих в сознании человека при создании или понимании определённого текста. Когнитивная трактовка схем, построенных на основе ТРС, изначально мыслилась авторами данной теории как вероятная, ряд последующих экспериментальных исследований предоставил аргументы в поддержку данной гипотезы [4].

Структура дальнейшего изложения такова. В следующем разделе очерчиваются границы исследования и уточняется его цель. В разделе «Теория риторической структуры» дана общая характеристика ТРС и принципов применения этой теории к стихотворным текстам. Далее в разделах «Сегментация» и «Идентификация отношений» следует детализация правил анализа текстов. В разделе «Языковой материал» приведены количественные характеристики рассмотренных текстов. Следующий раздел посвящён сравнительному анализу схем, соответствующих разным группам текстов. В заключении подведён итог проделанной работы и намечены возможные пути использования полученных данных.

\section{Проблемная ситуация}

Предваряя свою книгу о поэтическом тексте, Ю.М. Лотман отмечает, что задача науки состоит в правильной постановке вопросов [5. С. 6-8]. Вопрос должен формулироваться в терминах того раздела науки, в рамках которого данный вопрос предполагается решать. Иначе говоря, метаязык формулировки вопроса должен соответствовать метаязыку поиска и формулировки ответа. Такое требование, хотя и сужает исследование, делает его корректным в научном отношении, так как даёт возможность судить, был ли в результате получен ответ именно на тот вопрос, который был задан. Если ответ соответствует вопросу, то результатом является не только собственно ответ на интересовавший исследователей вопрос, но и разработанная в ходе этого процесса воспроизводимая методология получения ответа. Данное соображение Ю.М. Лотмана видится нам очень важным. Следуя ему, определим прежде всего тот исследовательский контекст, в рамках которого проведена представленная в статье работа, а затем сформулируем в соответствующих терминах цель этой работы.

Поэтический текст, как и многие другие виды текстов, многофункционален. Однако прежде чем изучать сложное взаимодействие присущих такому тексту функций, необходимо исследовать каждую функцию в отдельности. Для М.Ю. Лотмана [5] целью проведения структурного анализа поэтического текста является изучение способности такого текста выполнять эстетическую функцию. Текст при этом рассматривается как структурное целое. 
Помимо эстетической функции стихотворный текст выполняет также познавательную: «Стихотворство род познанья, возвышающего дух» ${ }^{1}$. Одним из инструментов изучения структуры познавательного процесса, отражённого в тексте, является теория риторической структуры. Риторические отношения мыслятся здесь как когнитивные сущности, «когнитивные механизмы», связывающие текст воедино в сознании говорящего и реконструируемые адресатом при понимании этого текста [4. С. 11].

Цель нашей работы состояла в изучении структур познавательных процессов, отражённых в стихотворном тексте, эстетическая функция не затрагивается. Абстрагирование от ведущей для такого типа текстов эстетической функции представляется оправданным, поскольку детальное изучение каждой функции в отдельности весьма трудоёмко и вместе с тем необходимо для развития комплексного синтезирующего взгляда.

Коммуникация - это не просто передача информации как набора фактов, а также побуждение адресата к познанию определенного аспекта мира. Это можно проиллюстрировать на примере такого жанра, как научная статья. Предназначение научной статьи, опубликованной для близкого в научном отношении сообщества исследователей, состоит не только в сообщении некоего готового результата, но также в том, чтобы побудить адресата пройти определённый путь познания, позволяющий оценить степень доверия к данному результату. Причём в научной статье автор должен выстроить и предложить адресату путь познания, отвечающий регламентирующим нормам, принятым в сфере науки, хотя этот путь может отличаться от реального пути, пройденного автором в ходе соответствующего исследования. В стихотворном тексте регламентирующие нормы значительно более свободны, и автор-поэт может отразить в своём произведении тот путь познания, который ценен или убедителен прежде всего для него самого.

Познавательный процесс, воплощаемый в тексте, гетерогенен как в плане формы, так и в плане содержания.

Участвующие в этом процессе составляющие могут относиться к разным аспектам языка. Между ними возможны взаимозависимости, в [6], например, обсуждаются связи между метрикой поэтического текста, семантикой, синтаксисом. Некоторые процедуры анализа стихотворных текстов поддаются алгоритмизации, нередко используются методы математической статистики. В качестве примера можно привести область стилеметрии. Так, в [7] рассмотрены лексико-семантический и синтаксический уровни. Формализованные процедуры изучения интересующего нас уровня прагматики стихотворного текста в таких исследованиях затрагиваются лишь косвенно, как правило, при анализе лексики. Однако прагматика представляет собой обширную область, выходящую за пределы лексики.

${ }^{1}$ Руставели Шота. Витязь в тигровой шкуре / пер. Н. Заболоцкого. М. : Худ. лит., 1969. С. 25. (Библиотека всемирной литературы. Серия первая: Литература Древнего Востока, Античного мира, Средних веков, Возрождения, XVII и XVIII вв. Т. 27). 
Относительно границ и содержания прагматики единого мнения не существует, но в любом случае в фокусе внимания находятся имплицитные составляющие содержания текста: «Прагматика... есть искусство анализа несказанного» (Pragmatics... is "the art of the analysis of the unsaid" [8. P. 2]. В нашем исследовании рассматриваются пропозициональные имплицитные составляющие, называемые реляционными пропозициями $[1,9]$. Такие пропозиции представляют собой утверждения о типе связи между частями текста. Иерархическая структура реляционных пропозиций, реконструируемая посредством построения схем ТРС, наиболее значима для анализа хода познавательного процесса, движения мысли, отображённого в тексте.

Познавательный процесс гетерогенен не только по языковой форме, но и по содержанию. Основа содержания текста - его логическая форма, т.е. представление смысла текста на каком-либо из метаязыков математической логики. Однако при описании содержания текста только посредством логической формы игнорируются компоненты, потенциально также способные участвовать в познании, например эмоции, интенции, оценки, восприятия, обращения к собеседнику.

Возникает вопрос об адекватном средстве представления такого гетерогенного познавательного процесса. Использование ТРС позволяет соединить все указанные виды составляющих, связывая в единой структуре когнитивные вклады различных типов.

Гетерогенность когнитивных составляющих прослеживается в эволюции представления о базовой модели коммуникации, менявшегося параллельно с расширением границ прагматики (как и лингвистики в целом) во второй половине XX в. Господствовавшая в середине XX в. модель Шеннона-Уивера [10], часто называемая «кодовой» и «механистической», представляющая процесс коммуникации как кодирование и декодирование информационного сообщения, была обогащена Г.П. Грайсом [11], трактовавшим коммуникацию как в значительной степени инференциальный процесс, обусловленный интенциями участников коммуникации. Следующее обогащение представления о коммуникации, расширившее её до остенсивно-инференциальной модели, связано с теорией релевантности Д. Спербера и Д. Уилсон, включивших в рассмотрение коммуникативные функции стимулов, относящихся к разным модальностям [12].

Представленная в данной статье работа не выходит за пределы текстовых данных и не учитывает других модальностей коммуникации. Вопрос о соотношении реляционных пропозиций с постулатами Г.П. Грайса не рассматривался, как и вопрос об уместности использования понятия остенсии в связи с ТРС. Можно лишь предположить, что модель коммуникации, на которую опирается обсуждаемое исследование, занимает промежуточное положение между инференциальной моделью Г.П. Грайса и остенсивноинференциальной моделью Д. Спербера и Д. Уилсон. Для более определённого суждения требуется дополнительный анализ данных теорий.

Таким образом, подводя итог сказанному, можно заключить, что цель данного исследования состоит в адаптации ТРС к анализу стихотворных 
текстов русского языка, применении этой теории к таким текстам, в изучении закономерностей, проявляющихся на пропозициональном уровне и представленных в иерархической структуре реляционных пропозиций, обеспечивающих связность и целостность стихотворного текста.

Согласно априорной гипотезе, положенной в основу исследования, анализ закономерностей в таких структурах позволяет выявлять общие и специфичные свойства стихотворных текстов.

В заключение данного раздела обратим внимание на одну семиотическую особенность стихотворных текстов. Развивая рассуждение Ю.М. Лотмана [5] о семиотическом потенциале языковых единиц, используемых в стихотворном тексте, Р. Познер рассуждает о «семиотической новизне» [13. С. 166] языковой формы такого текста, осознаваемой даже после того, как текст уже понят.

Эта мысль представляется важной, поэтому позволим себе её интерпретацию и развитие. Стихотворный текст часто включает окказиональные семиотические построения, созданные автором именно для этого текста, не встречавшиеся ранее и ещё не успевшие стать конвенциональными. Такие составляющие в той или иной степени нуждаются в распознавании, разгадывании. Соответственно, при чтении стихотворения движение мысли не идёт по уже проторённым путям, а прокладывает новые, создаёт некий (структурно и содержательно) новый мыслимый мир, и в этом видится одна из причин притягательности поэзии.

В связи с отмеченной выше неустранимостью новаторских семиотических аспектов из итогового понимания текста уместно вспомнить об одном из свойств знака, а именно о принципе прозрачности, сформулированном Леоном Коем [14]. Согласно принципу прозрачности любой знак в момент усмотрения его содержания утрачивает свои материальные характеристики, становясь «прозрачным» для восприятия этого содержания. Иначе говоря, семиотический путь, приведший к пониманию определённого содержания, становится ненужным и отбрасывается после того, как это содержание понято. Внимание направляется на то, на что указывает знак, а не на сам знак.

Если новаторские семиотические аспекты стихотворного текста неустранимы из его итогового понимания, то это означает, что принцип прозрачности к стихотворным текстам в полной мере не применим. Знак здесь менее прозрачен, чем в других видах текстов. Благодаря своей нестандартности знак не покидает область внимания, как это обычно происходит, например, при деловом общении, если внимание собеседников направлено на суть обсуждаемого вопроса.

Семиотическая новизна теоретически может проявляться на каждом из уровней языковой системы, затрагивая фонетические, просодические, лексические, синтаксические, семантические, прагматические аспекты. В частности, она может проявляться в ракурсах и траекториях движения мысли. Неустранимость новаторских аспектов этого уровня означает, что они запечатлены в итоговом понимании стихотворного текста. Иначе го- 
воря, понимая такой текст, мы не теряем из вида путь, приведший к этому пониманию. Реконструкции таких путей посвящено данное исследование.

\section{Теория риторической структуры}

Теория риторической структуры была предложена Уильямом Манном и Сандрой Томпсон в середине 80-х гг. ХХ в. Уже более тридцати лет она активно используется для решения широкого круга задач, в частности из области автоматического анализа текстов (Natural language processing, NLP) и корпусной лингвистики. Конкретный перечень сфер приложения данной теории можно найти в обзорной статье [15] и её дополнении [4]. Среди разнообразных видов текстов, исследуемых посредством ТРС, можно встретить прозаические художественные сочинения (например, изучение манипуляторных «игр» с читателем в произведениях Агаты Кристи [16]), но нет применений для анализа стихотворных текстов, что, скорее всего, объясняется изначальной установкой авторов, ориентировавшихся прежде всего на область NLP и актуальные задачи этой области, а именно автоматическое реферирование, генерацию текста, снятие неоднозначностей и т.д.

Авторы ТРС исключали из рассмотрения стихотворные тексты типа «язык-как-искусство» («language-as-art») [1. С. 20], к которым можно отнести поэзию авангарда, основанную на экспериментировании с языком, например произведения В. Хлебникова. Очевидно, что к данной категории относятся не все стихотворные тексты. Однако, по-видимому, в силу сложившейся традиции исследования применимости ТРС к поэтическим текстам единичны. Была обнаружена только одна работа, посвящённая анализу на основе ТРС нарративных стихотворных текстов на китайском языке [17]. Вместе с тем нет оснований априорно отвергать возможность применения ТРС и к лирическим стихотворным текстам. Изучение данного вопроса в [18] позволило прийти к позитивному выводу о возможности такого применения ТРС.

Теория риторической структуры основана на предположении о том, что связный текст представим в виде последовательности сегментов, каждый из которых функционально значим для понимания текста в целом, и все сегменты в совокупности, благодаря связывающим их реляционным пропозициям, образуют единую иерархическую структуру, изображаемую в виде дерева. Набор возможных отношений (типов связей) один и тот же на всех уровнях структуры.

Сегменты могут быть элементарными или сложными. Сложный сегмент соответствует подструктуре структуры всего текста в целом.

В работах о применении ТРС к текстам русского языка (например, [3, 19, 20]) принято использовать термины «элементарная дискурсивная единица (ЭДЕ)» и «дискурсивная единица» для обозначения соответственно элементарного сегмента и любого сегмента (элементарного или сложного). Применительно к стихотворным текстам русского языка была разработана специальная процедура анализа, учитывающая специфику таких текстов и 
отличающаяся от принципов анализа прозаических текстов. Поэтому указанные традиционные термины не использовались, чтобы не размывать их общепринятые трактовки. Далее будут использоваться только наименования «элементарный сегмент» и «сегмент».

Рассмотрим для иллюстрации схему, построенную в результате анализа стихотворения Генриха Гейне в переводе А.К. Толстого (рис. 1). Принципы установления отношений, в частности в этой структуре, обсуждаются в следующем разделе статьи.

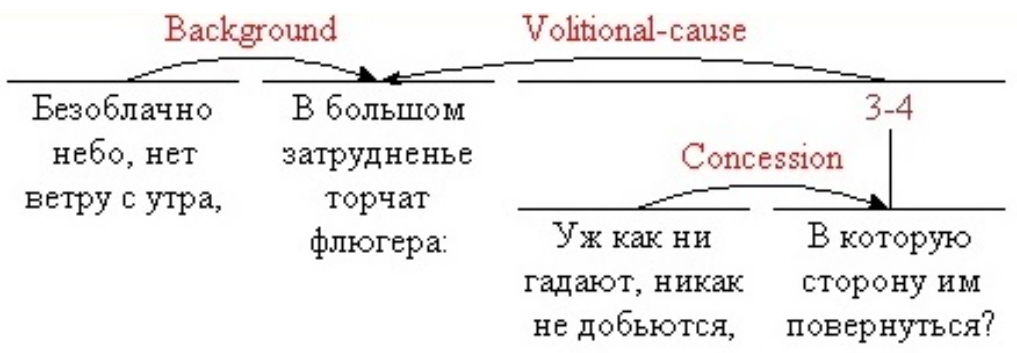

Рис. 1. Схема стихотворения Г. Гейне (перевод А.К. Толстого)

Текст данного стихотворения разделён на четыре элементарных сегмента, соответствующих строкам стихотворения. Элементарные сегменты нумеруются слева направо. При объединении сегментов в более сложную единую структуру (сложный сегмент) номера входящих в эту структуру элементарных сегментов указываются в её главной вершине. Например, на рис. 1 надпись 3-4 означает, что данный сложный сегмент объединяет в себе элементарные сегменты 3 и 4.

В тексте стихотворения Г. Гейне нет явной информации о том, как функционально связаны между собой сегменты и связаны ли они вообще. Нет явных индикаторов (дискурсивных маркеров) какой-либо связи, например союзов «так как», «поэтому», позволяющих идентифицировать причинно-следственную связь. Есть лишь двоеточие в конце второго сегмента, но оно не является однозначным индикатором именно причинноследственной связи и может иметь другие трактовки. Вместе с тем, читая и понимая данный текст, мы усматриваем связи между сегментами, в частности, нам ясно, что в стихотворении объясняется, почему именно флюгера находятся «в затрудненье».

Такое понимание достигается благодаря реляционным пропозициям: мы как бы «насыщаем» ими текст, делая его связным. Реляционные пропозиции соответствуют дугам, связывающим сегменты, и образуют каркас данной схемы, без которого она распалась бы на отдельные сегменты. Понимание текста адресатом включает реконструкцию реляционных пропозиций. Как и всякий аспект понимания, такая реконструкция может допускать варианты и не вполне совпадать с авторской.

Отношения между сегментами подразделяются на асимметричные и симметричные. Отношение первого типа ставит один сегмент (сателлит) в 
подчинение другому сегменту (ядру), на схеме такое отношение отображается в виде стрелки. Стрелка направлена от подчинённого сегмента к главному. Отношение второго типа связывает два или более равноправных сегмента, ни один из которых не подчинён другому, такое отношение изображается на схеме в виде линии без стрелки.

В зависимости от выполняемой функции отношения подразделяются на предметные отношения (subject matter relations) и отношениявоздействия (presentational relations). В [1. С. 17] предлагается также первые называть семантическими, а вторые - прагматическими. Все симметричные отношения относятся к числу предметных. Предметное отношение выполняет функцию информирования о фактах: оно отражает обсуждаемую ситуацию. Асимметричное отношение-воздействие используется автором текста для того, чтобы склонить адресата к принятию мысли, выраженной в сегменте-ядре. Например, Background трактуется как отношение-воздействие, посредством него автор текста задаёт фоновую информацию, которая, по его мнению, облегчит понимание сказанного в сегменте-ядре.

Для использования ТРС применительно к определённому классу текстов необходимо ответить на три вопроса:

- Как делить текст на элементарные сегменты?

- Какие отношения использовать при построении схем?

- На основе каких критериев идентифицировать эти отношения?

Обсуждению этих вопросов посвящены следующие два раздела статьи.

Длительный опыт использования ТРС продемонстрировал высокую степень универсальности набора отношений, предложенного в традиционной версии ТРС [1] и проверен на большом объёме разнообразных текстов. Этот набор отношений был взят за основу и в данном исследовании. Вместе с тем авторы ТРС подчёркивали, что список отношений не следует рассматривать как раз и навсегда зафиксированный: новый вид текстов и новые задачи могут обусловить изменение состава отношений.

Выработка критериев идентификации отношений базировалась на следующих положениях.

1. За основу были взяты определения отношений и критерии их идентификации, сформулированные авторами ТРС в [1].

2. При уточнении множества отношений и критериев их идентификации ведущим принципом было достижение единообразия анализа всего массива текстов, обеспечивающее воспроизводимость результатов. Важность этого принципа подчёркивали авторы ТРС [1]. Соблюдение его было основной причиной трудоёмкости решения поставленной задачи, так как для выработки воспроизводимых критериев потребовались многократные итеративные просмотры всех построенных структур.

3. При выработке правил построения схем было принято во внимание последующее сравнение стихотворных и прозаических текстов: несмотря на различия в правилах построения схем для этих двух видов текстов, результирующие схемы сравнимы. 
4. Были добавлены два новых общих критерия идентификации отношений при отсутствии однозначного текстового индикатора:

а) возможность синонимического преобразования текста с введением однозначного индикатора отношения;

б) проверка согласованности смысла текста с пропозициональной логической формой, соответствующей отношению.

Поясним добавленные два критерия.

В некоторых случаях отношение, связывающее сегменты, идентифицировать несложно, так как в тексте имеется однозначный идентификатор этого отношения. Например, в следующем фрагменте стихотворения А.К. Толстого «По гребле неровной и тряской» уступительный союз хоть служит однозначным индикатором отношения Concession (Уступка): Мне кажется всё так знакомо, / Хоть не был я здесь никогда. Однако, как показали многочисленные эмпирические исследования $[15,21,22]$, такие ситуации встречаются нечасто. Некоторые виды отношений вообще, как правило, не имеют текстовых индикаторов. В случае отсутствия или неоднозначности индикатора можно попытаться перефразировать текст, высказав ту же мысль иначе. Например, в следующем фрагменте стихотворения А.К. Толстого «Когда кругом безмолвен лес дремучий» вставка союза так как перед вторым сегментом не меняет смысл сказанного, но явным образом показывает причинно-следственную связь между сегментами: И трудно мне умом понять разлуку, / Ты так близка.

Как уже было сказано, воплощённый в тексте познавательный процесс гетерогенный, его составляющие не сводятся только к логической форме. Однако более или менее явная логическая основа в них всегда присутствует. Поэтому исследователь, интересующийся логикой рассуждения, может мысленно изолировать логическую форму текста, оставляя за пределами своего внимания остальные составляющие. Действуя таким образом, автор [23] предложил систему соответствий для отношений, используемых в ТРС, уподобив каждое отношение определённой формуле пропозициональной логики. Использование этих соответствий в обратном направлении послужило одним из критериев идентификации отношений в стихотворных и прозаических текстах.

\section{Сегментация текста}

Детальная разработка принципов сегментации текста на «кванты» мысли и критериев идентификации отношений представлена в исследовании [3], ориентированном на анализ устной речи на русском языке. Есть ряд исследований на материале других типов прозаических текстов русского языка (новостных, научно-популярных, научных), например [19, 20]. Однако стихотворные тексты обладают своей спецификой, которую необходимо учитывать при их анализе на основе ТРС. Особенность таких текстов состоит прежде всего в делении на строки. Кроме этого, для таких текстов характерны абстрагированность, рассуждения о непредметном мире, что 
осложняет идентификацию отношений и делает необходимой разработку уточнённых критериев их различения, основанных скорее на семантических, прагматических и логических, а не на синтаксических и лексических аспектах (на которых обычно акцентируют внимание разработчики средств автоматического анализа текстов).

Деление стихотворного текста на строки является структурной особенностью таких текстов, оно связано с просодической, синтаксической, семантической структурами и, значит, является информативным. В исследовании, проведённом посредством ТРС на материале стихотворных текстов китайского языка [17], деление на строки было сохранено при сегментации текста. В [18] оно также, как правило, сохранялось, хотя допускались исключения.

Строка стихотворения может разрывать синтаксически связанные части предложения или, наоборот, объединять в себе ряд предложений. Разрыв синтаксической связи может возникнуть и в прозаическом тексте, например в случае вложенных конструкций. Правда, в проанализированных прозаических текстах такие случаи встречаются значительно реже, чем в стихотворных.

В данном исследовании при сегментации стихотворного текста деление на строки было сохранено. Оно принималось во внимание при сопоставлении разных групп таких текстов. Вместе с тем при сравнении стихотворных и прозаических текстов деление на строки, разрушающее синтаксические связи, можно было исключить из рассмотрения.

Границей между элементарными сегментами считались конец строки или знак препинания, обозначающий конец предложения (точка, многоточие, восклицательный или вопросительный знак).

Строка стихотворения может соотноситься с пропозициями по-разному. Она может выражать: а) одну или более пропозиций полностью; б) пропозициональную форму (т.е. пропозицию с некоторым числом незаполненных аргументных мест); в) аргумент (аргументы) предиката, входящего в состав другой строки стихотворения, или свойства такого аргумента. Возможны смешанные варианты, например в строке имеется одна полная пропозиция и аргумент от другой пропозиции.

Так, в следующем тексте аргумент указан в первой из строк, предикат во второй Телега с разбитой лошадкой / Лениво подвозит мешки (А.К. Толстой «По гребле неровной и тряской»). Во фрагменте Неотвязчивый кружится / Над тобой комар, наоборот, предикат находится в первой строке, а аргумент - во второй (А.К. Толстой «Милый друг, тебе не спится»). В следующем примере строка стихотворения А.К. Толстого «Когда природа вся трепещет» делится на два сегмента, так как внутри неё есть точка: И в ближний лес вхожу. Там покрасневший клён.

При разрыве предложения и отнесении его частей к разным сегментам для связывания этих сегментов могут использоваться разные отношения, это определяется содержанием соответствующей реляционной пропозиции. Если строка разделяет предложение на две части, причём предикат 
попадает во вторую часть и первая не имеет ясного завершённого смысла, то первая часть трактуется как сателлит второй, соединяясь с ней отношением Preparation. Однако при разрыве синтаксической связи возможны и другие типы отношений. Например, в следующих текстах однородные предикаты оказываются в разных строках и в разных сегментах. В первом случае сегменты связаны отношением Conjunction: Неровный круг планета совершила / И к солниу снова катится назад (А.К. Толстой, «Я вас узнал»). Во втором примере это отношение Disjunction: Меж людей он добрый воин / Или мирный гражданин (А.К. Толстой, «В жизни светской»).

\section{Идентификация отношений}

Для единообразия проводимого анализа текстов потребовалось детализировать условия использования отношений, сформулировав правила их дифференциации. Далее рассмотрено несколько групп отношений, связанных по своему содержанию и зачастую непросто различимых. При анализе дифференцирующих признаков таких отношений использовались определения из [1] и параллели между отношениями и логическими формулами из [23].

Синонимические преобразования и соотнесения с логической формой применимы при дифференциации любых отношений. Ниже эти возможности проиллюстрированы только для некоторых отношений, чтобы чрезмерно не увеличивать объём статьи.

Для определения направления связи использовался критерий авторов ТРС [1]: устранение сателлита в меньшей степени разрушает понятность текста, чем устранение ядра.

Для наименования отношений служили англоязычные названия из [1], так как эти термины стали традиционными для публикаций о ТРС, включая публикации на русском языке. При первом упоминании отношения в скобках указан переводной аналог, для большинства отношений это перевод, использованный в [3].

1. Предваряющая и дополняющая информация об обсуждаемой ситуации: Background (Фон), Preparation (Подготовка), Circumstance (Обстоятельство), Elaboration (Детализация).

В случае использования отношения Background сателлит задаёт фон, необходимый для понимания ядра. Это могут быть какие-то сопутствующие события, ситуации, состояния. Например: Дорожная едет коляска (сателлит) / Сижу я задумчиво в ней (ядро) (А.К. Толстой. «По гребле неровной и тряской»). Без сателлита ситуация, представленная в ядре, была бы менее понятной. Отношение Background имеет логическую форму вида modus ponens: $((\mathrm{S} \rightarrow \mathrm{N}) \wedge \mathrm{S}) \rightarrow \mathrm{N}$, где символ импликации трактуется как отношение понятности (если понятно $\mathrm{S}$, то понятно и $\mathrm{N}$ ). Здесь и далее символом $\mathrm{S}$ обозначается сателлит, символом $\mathrm{N}$ - ядро, в случае многоядерного отношения используется символ N с индексом. Background относится к числу отношений-воздействий, при выборе $\mathrm{S}$ автор текста, ориентируясь 
на когнитивные способности адресата, подбирает информацию, которая, как он полагает, облегчает понимание N.

Отношение Preparation по своему изначальному смыслу [1] готовит к восприятию ситуации, представленной в ядре, но делает это менее определённым образом, чем отношение Background: оно не задаёт фон, а привлекает внимание к чему-либо, чтобы адресат мог решить, читать ли текст далее. Однако в данной работе отношение Preparation использовалось в суженном (по сравнению с [1]) варианте, а именно только в случае разрыва синтаксической связи, возникшего из-за проведения границы между сегментами внутри предложения. Сателлит здесь есть средство подготовки адресата к прочтению следующего текста. Как уже было сказано, такие ситуации встречаются как в стихотворных, так и в прозаических текстах. Иллюстрацией могут служить следующие примеры.

В схеме, построенной для стихотворения А.К. Толстого «В жизни светской», использовано отношение Preparation: Но порой мечтою странной (сателлит) / Он томится одинок (ядро). Без второй строки первая строка неясна, она не описывает ситуацию понятным образом. То же самое можно сказать о сегменте $O m$ Львовых, который оказался оторванным от остальной части предложения уточнением в скобках: Om Львовых (которые приехали) я ничего не мог узнать (фрагмент письма А.К. Толстого к В.М. Лазаревскому, 1865 г.). На рис. 2 приведён фрагмент схемы для сегментов 30-32. Здесь сегмент 30 (Спокойствием объятый) представляет свойство актанта предиката, вошедшего в другой сегмент. Поэтому использовано отношение Preparation. Отношение, связывающее получившуюся конструкцию с сегментом 32, идентифицировано как Background, поскольку сложный сегмент 30-31 содержит одну полную пропозицию. Если бы здесь был только актант без полной пропозиции, то отношение было бы идентифицировано как Preparation.

Отношение Circumstance обстоятельственное, оно входит в множество предметных отношений, служащих для информирования о фактах, без намерения оказать какое-либо дополнительное воздействие на адресата. Сателлит $\mathrm{S}$ задаёт границы локализации ситуации, представленной ядром N. Чаще всего это границы во времени и/или пространстве. Этому отношению соответствует логическая форма вида $(\mathrm{S} \wedge \mathrm{N}) \wedge(\mathrm{S} \rightarrow \mathrm{N})$. Символ импликации здесь трактуется предметно, как соотношение локализаций: из того, что задана локализация S, следует, что это есть локализация N. B примере из того же стихотворения «По гребле неровной и тряской» сателлит связан с ядром отношением Circumstance: Близ мельницы старой и шаткой (сателлит) / Сидят на траве мужики (ядро).

Отношение Circumstance, подобно отношениям Preparation и Elaboration, может использоваться в случае разрыва синтаксической связи, обусловленного разделением стихотворного текста на строки. Поэтому все три отношения использовались при сравнении стихотворных текстов между собой, но были исключены из рассмотрения при проведении сравнительного анализа стихотворных и прозаических текстов. 


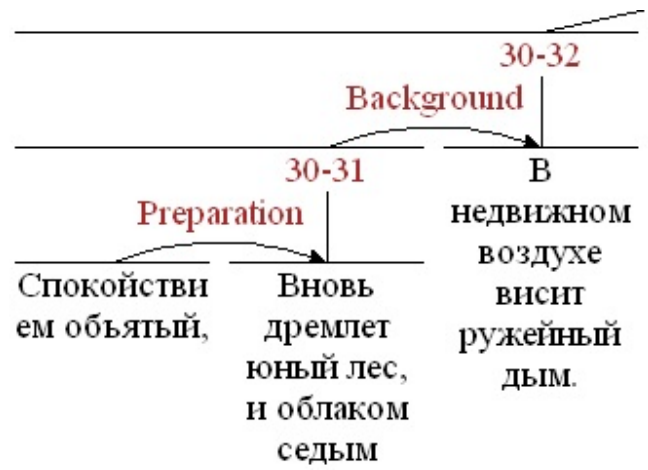

Рис. 2. Фрагмент схемы стихотворения А.К. Толстого «Сквозит на зареве темнеющих небес»

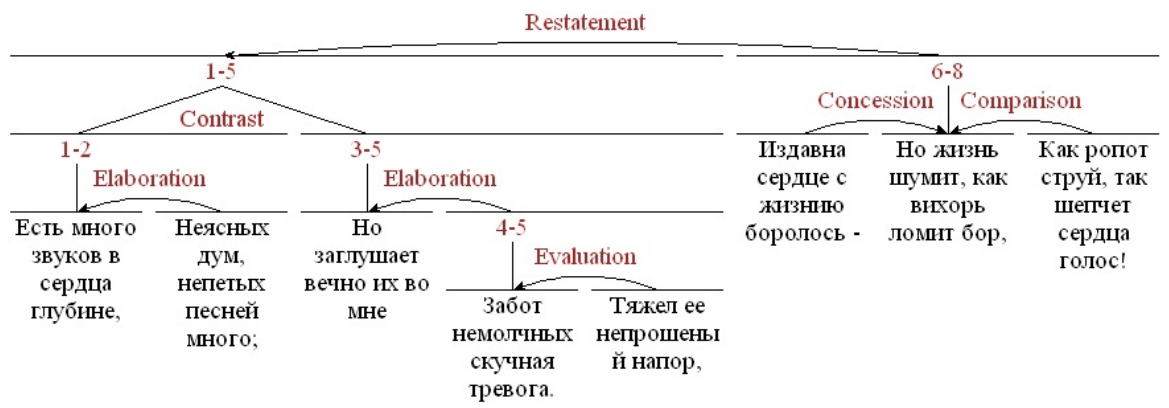

Рис. 3. Схема стихотворения А.К. Толстого «Есть много звуков в сердца глубине»

Отношение Elaboration относится к числу предметных, это информирование о фактах. Сателлит добавляет информацию о ситуации, уже представленной ранее в ядре, уточняя какие-либо её характеристики. Смысловая связь между ядром и сателлитом может характеризоваться как общеечастное, объект-атрибут, процесс-этап, элемент-множество, абстракцияреализация. Например, О том поведать не могу я (ядро) / На ежедневном языке (сателлит) (А.К. Толстой «Судя меня довольно строго»). Отношение Elaboration может использоваться при разрыве синтаксической связи, если актант и предикат оказываются в разных сегментах, но ядро данного отношения понятно даже в отсутствие актанта и содержит предикат. Примером может служить часть схемы на рис. 3 (сегменты 3-5). Как правило, при отношении Background сателлит предшествует ядру, а при отношении Elaboration, наоборот, ядро предшествует сателлиту.

2. Совместное рассмотрение ситуаций: Conjunction (Конъюнкция), Joint (Соединение), Sequence (Последовательность), Contrast (Сопоставление), Disjunction (Дизъюнкция), Concession (Уступка), Antithesis (Антитезис), Otherwise (Альтернатива). 
Разграничение отношений данной группы представляло наибольшие сложности. Первые четыре отношения соответствуют конъюнкции и являются симметричными, т.е. связывают только ядра и не имеют сателлитов. К ним примыкает симметричное отношение дизъюнкции. Эти пять отношений, а также асимметричные отношения Condition и Otherwise относятся к предметным, их назначение - информировать адресата об определённых фактах. Concession и Antithesis - асимметричные отношениявоздействия.

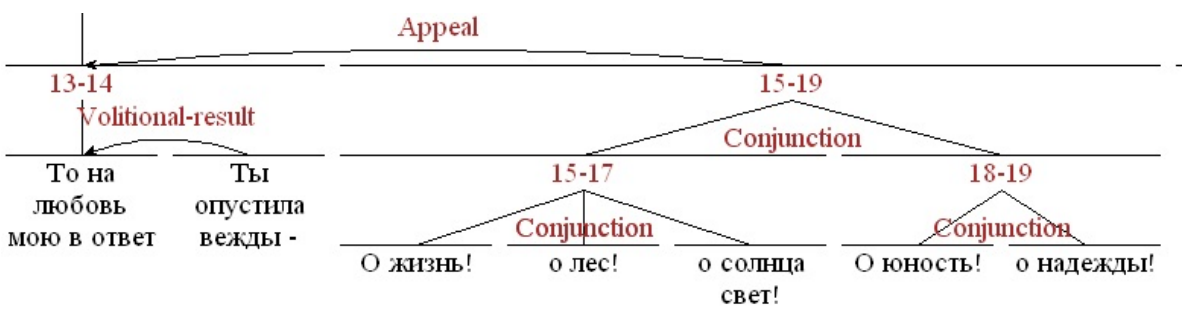

Рис. 4. Фрагмент схемы стихотворения А.К. Толстого «То было раннею весной»

Отношение Conjunction соответствует конъюнкция, при которой конъюнкты связаны между собой содержательно. Как видно по примеру на рис. 4 , деление на строки учитывается: конъюнкты, соответствующие сегментам, размещённым в одной строке стихотворения, считаются связанными более тесно, чем сегменты-конъюнкты из разных строк ( $O$ жизнь! $о$ лес! о солния свет! / О юность! о надеждь!!). Отношение Јoint также означает конъюнкцию, но конъюнкты в этом случае связаны не содержательно, а лишь своим вхождением в один и тот же текст, предназначенный для определённого адресата. Этот вариант конъюнкции нередко встречается в письмах, когда автор по ходу написания письма переходит от одной темы к другой, никак не связывая их между собой по сути.

Sequence похоже на отношение Conjunction, но в отличие от него базируется на каком-либо упорядочении ситуаций. Это может быть, например, упорядочение по времени: Неровный круг планета совершила (ядро 1) / Ик солнщу снова катится назад (ядро 2) (А.К. Толстой «Я вас узнал, святые убежденья»).

Отношение Contrast также по смыслу является конъюнкцией, но в данном случае конъюнкты - это ситуации, в каком-то отношении противопоставляемые, хотя обычно совместимые. Например, Вчера два раза был у Bac... (ядро 1) но вас не было дома (ядро 2) (из письма А.К. Толстого к В.М. Лазаревскому, 1862 г.).

Отношение Disjunction не вызвало сложностей при идентификации, поэтому достаточно проиллюстрировать его примером: Когда упрёк мне шепчет шелест нивь (ядро 1) / Иль шум дерев (ядро 2) (А.К. Толстой. «Когда кругом безмолвен лес дремучий»).

Двухъядерное симметричное отношение Contrast похоже на одноядерное асимметричное отношение Concession. Самым явным индикатором 
отношения Concession является союз «хотя», например: ...хотя много служат личной характеристике Иоанна, (сателлит) но не имеют влияния на обший ход событий (ядро) (А.К. Толстой. «Князь Серебряный». Предисловие). Однако в случае отсутствия этого союза указанные два отношения различить бывает непросто, так как при реализации обоих может использоваться союз «но».

Для лучшего понимания различия между этими двумя отношениями нужно учесть то, что логические формы у них разные: отношению Contrast соответствует конъюнкция $\mathrm{N}_{1} \wedge \mathrm{N}_{2}$, отношению Concession - формула вида modus ponens $((\neg(\mathrm{S} \rightarrow \neg \mathrm{N}) \rightarrow \mathrm{N}) \wedge \neg(\mathrm{S} \rightarrow \neg \mathrm{N})) \rightarrow \mathrm{N}$ (заметим, что использование обозначения $\mathrm{P}=\neg(\mathrm{S} \rightarrow \neg \mathrm{N})$ позволяет свести исходную формулу к виду $((\mathrm{P} \rightarrow \mathrm{N}) \wedge \mathrm{P}) \rightarrow \mathrm{N}$, т.е. к формуле вида modus ponens). Кроме того, Contrast является предметным отношением и служит для осведомления о фактах, а не для воздействия на адресата с целью его убеждения в чём-то (как Concession). В случае Concession импликация вида A $\rightarrow$ B трактуется не предметно, а как отношение убедительности, т.е. означает, что из убедительности А следует убедительность В. Автор текста подбирает такое содержание сателлита, которое, как он полагает, может побудить адресата принять ситуацию, представленную в ядре.

При использовании отношения Contrast акцент внимания направлен просто на констатацию факта наличия двух в чём-то противопоставляемых ситуаций. При использовании Concession дополнительно акцентируется неравнозначность этих ситуаций и их кажущаяся несовместимость. Сателлит служит для усиления, обогащения восприятия ядра, более вероятного принятия его адресатом. Хорошей иллюстрацией может служить стихотворение на рис. 2. В сегментах 1-5 наличие двух ситуаций констатируется, в сегментах 6-8 акцентирована их борьба и выделена наиболее значимая из них, сегмент 6 предназначен для большей убедительности содержания сегмента 7.

Отношения Contrast, Concession, Antithesis, Otherwise, Condition различаются по сравнительной значимости сопоставляемых ситуаций и по тому, реализованы эти ситуации или нет. Кроме того, эти отношения можно упорядочить по степени совместимости сополагаемых ситуаций.

В случаe Contrast эти ситуации одинаково значимы и могут быть совместимыми, но противопоставленными по некоторому признаку. В случаe Concession сателлит представляет подчинённую ситуации, кажущуюся несовместимой с ситуацией, представленной ядром, однако на самом деле эти две ситуации совместимы. В случае Antithesis ситуации действительно несовместимы, при этом сателлит представляет нереализованную ситуацию, и её отрицание используется для побуждения адресата к принятию ситуации, представленной ядром. Например По-прежнему сияет правды сила, (ядро) / Её сомненья боле не затмят (сателлит) (А.К. Толстой. «Я вас узнал, святые убежденья»). Логической формой отношения Antithesis является дизъюнктивный силлогизм: $((\mathrm{S} \vee N) \wedge \neg \mathrm{S}) \rightarrow \mathrm{N}$. 
Otherwise, в отличие от отношения-воздействия Antithesis, является предметным отношением, его логическая форма - исключающая дизъюнкция $\mathrm{N} \oplus \mathrm{S}$, или, иначе, $(\mathrm{N} \vee \mathrm{S}) \wedge \neg(\mathrm{N} \wedge \mathrm{S})$. Otherwise - это сопоставление двух альтернативных ситуаций, причём обе они являются нереализованными. Одна из этих ситуаций (ядро N) мыслится как более значимая и предотвращающая ситуацию, представленную в сателлите. Например: Неэра, не вверяй себя морским волнам, (ядро) / Не то богинею ты станешь... (сателлит) (А. Шенье. «Ко мне, младой Хромид», перевод А.К. Толстого).

3. Коммуникация, восприятие, мышление: Appeal (Обращение), Warning (Предостережение), Attitude (Установка), Content (Содержание), Promise (Обещание), Directive (Указание). Все эти отношения отсутствуют в первоначальном списке отношений ТРС [1]. Отношение Content используется в [3]. Остальные отношения являются новыми.

Appeal (рис. 4) использовано в тех случаях, когда сателлит представляет собой риторическое обращение (призыв или вопрос к себе, к другим, к высшим силам). Риторическое обращение не требует ответа. Оно нередко встречается в стихотворных текстах и бывает спровоцировано определённой ситуацией, будучи её следствием. Причём для понимания текста в целом важнее именно эта провоцирующая ситуация, поэтому представляющий её сегмент является ядром.

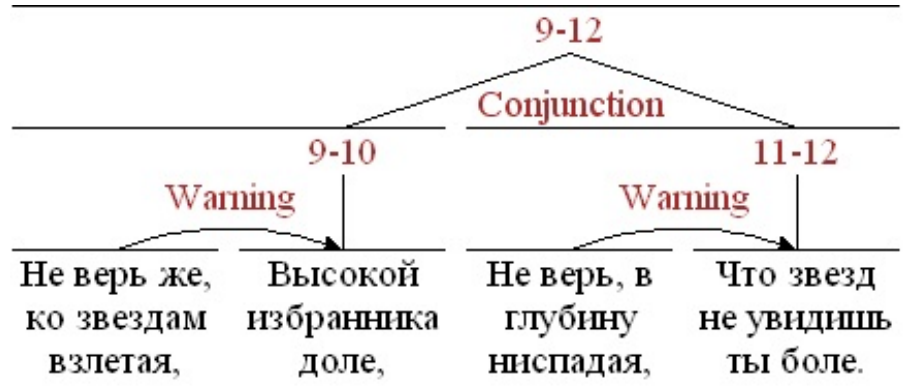

Рис. 5. Схема стихотворения А.К. Толстого «Вздымаются волны как горы»

Риторическое предостережение Warning, подобно Appeal, не требует ответа, но в отличие от него, как правило, негативно, т.е. служит для настраивания адресата против осуществления определённого действия или принятия пропозициональной установки (рис. 5). Warning, как и Appeal, входит в число отношений-воздействий.

Отношения Attitude, Content, Directive также входят в число отношений-воздействий.

Attitude указывает на пропозициональную установку (знание, верование, желание, намерение и т.д.). Оно используется в том случае, если усматриваемое содержание пропозициональной установки более существенно для понимания текста как целого, чем способ усмотрения этого содержания. Например, Узнав, (сателлит) что Ваш брат, Александр Mam- 
веевич, ищет места посредника в Черниговской губернии... (ядро) (из письма А.К. Толстого к В.М. Лазаревскому, 1861 г.).

В случае пропозициональной установки обычно имеется соответствующий глагол, например глагол говорения, ментальный глагол, глагол перцептивного восприятия. При риторическом обращении такой глагол, как правило, отсутствует.

Примером отношения Content может служить фрагмент из стихотворения А.К. Толстого «К твоим, царица, я ногам»): Я мыслил, песни те слагая: (ядро) / Они неведомо замрут (сателлит). Отношение Content похоже на Elaboration, но в отличие от него характеризует субъективные факты внутреннего мира (предмет знания, понимания, мышления, видения, чувствования и т.д.).

Все проанализированные тексты были монологическими, поэтому не возникла необходимость выработки общих принципов отображения речевых актов. Были введены лишь те отношения, которые оказались актуальными для рассмотренных текстов.

Отношение Promise используется в случае речевого акта обещания, например: К тому времени, может быть, у меня будут новые собаки, (ядро) и я с истинным удовольствием поднесу Вам нового щенка взамен украденного (сателлит) (из письма А.К. Толстого к В.М. Лазаревскому, 1865 г.).

Отношение Directive используется в случае директивного речевого акта (просьба, приказ и т.д.), адресованного, в отличие от риторического Appeal, конкретному адресату (индивидуальному или коллективному), например: ...но я от них отказываюсь (ядро), что прошу Вас сообщить Великанову (сателлит) (из письма А.К. Толстого к В.М. Лазаревскому, 1865 г.).

4. Причинно-следственные зависимости, целеполагание: Non-volitional cause (Неволитивная причина), Non-volitional result (Неволитивный результат), Volitional cause (Волитивная причина), Volitional result (Волитивный результат), Condition (Условие), Purpose (Цель).

Bсе эти отношения являются предметными. Их идентификация не нуждается в детальных комментариях. В случае неясностей используется критерий перефразирования, т.е. проверяется, можно ли, сохраняя смысл анализируемого предложения, преобразовать его к виду, включающему индикатор соответствующего отношения (один из союзов так как, поскольку, поэтому и т.д.). Например, для следующего фрагмента стихотворения А.К. Толстого «Я вас узнал, святые убежденья» можно построить синонимичный текст, имеющий союз так как в составе сегмента-сателлита: Pacсеялся туман и, слава богу, (сателлит) / Я выхожу на старую дорогу (ядро). Выбор между Non-volitional и Volitional определяется тем, зависит ли причина / следствие от воли деятеля или нет. В случае персонификации какого-либо неодушевлённого объекта, явления, процесса используются волитивные варианты, иллюстрацией может служить пример на рис. 1.

Оба варианта Cause и Result (волитивный и неволитивный) можно рассматривать как подтипы отношения Elaboration, но с причинно- 
следственным аспектом. В случае Elaboration сателлит детализирует понимание ядра, описывая его дополнительные характеристики, причинноследственные отношения детализируют это понимание, отвечая на вопрос «почему?» или «что из этого следует?».

Condition - предметное отношение, оно служит для информирования адресата об условии реализации определённой ситуации. Например: ...Лишь только она будет напечатана... (сателлит) то непременно попрошу Вас принять от меня экземпляр (ядро) (из письма А.К. Толстого к В.М. Лазаревскому, 1865 г.). Стоит отметить, что по своей логической форме это отношение соответствует не импликации, а эквивалентности $\mathrm{S} \leftrightarrow \mathrm{N}$, поскольку помимо явно выраженной в тексте импликации $\mathrm{S} \rightarrow \mathrm{N}$ верна и обратная импликация $\mathrm{N} \rightarrow \mathrm{S}$.

Отношение Purpose представляет ситуацию, заданную сателлитом, как цель действия, представленного в ядре; сателлит отвечает на вопрос «зачем?», «для чего?»: Представляемый здесь рассказ (ядро) имеет иелию не столько описание каких-либо событий... (сателлит) (А.К. Толстой. «Князь Серебряный». Предисловие). В этом примере текст содержит индикатор отношения Purpose (имеет цеелию), однако, как и в случае других отношений, такой индикатор есть далеко не всегда: Помедли, дай списать чешуйный твой узор: (ядро) / Хочу для девы я холодной и красивой / Счеканить по тебе причудливый убор (сателлит) (А.К. Толстой. «Змея, что по скалам влечёшь свои извивы»).

5. Аргументация: Evidence (Свидетельство), Justify (Обоснование), Моtivation (Мотивация).

В случае использования каждого из этих отношений-воздействий речь идёт о будущей ситуации, которая пока ещё не состоялась. В этом их основное отличие от причинно-следственных отношений, устанавливающих связи между уже имеющимися ситуациями. Используя отношениявоздействия Evidence, Justify, Motivation, автор стремится побудить адресата принять ситуацию, представленную в ядре, но делает это разными способами, прибегая к разным типам воздействия. В случае Evidence аргументом является факт, представленный сателлитом, например: ...я полагаю, что брат Ваш на меня за это не рассердится. (ядро) Я его ни в чём не компрометировал (сателлит) (из письма А.К. Толстого к B.М. Лазаревскому, 1865 г.). В случае Justify автор утверждает обоснованность и правомерность своего заключения о ситуации, представленной в ядре, апеллируя к своим чувствам, опыту, осведомлённости и т.д. Для иллюстрации можно привести фрагмент стихотворения А. К. Толстого «Как здесь хорошо и приятно»: Как здесь хорошо и приятно, (ядро) / Как запах дерев я люблю... (сателлит). В случае Motivation автор стремится мотивировать адресата, апеллируя к его интересам, чувствам, стремлениям, например: Подойди сюда к окошку (ядро) / Всё кругом молчит... (сателлит) (А.К. Толстой. «Милый друг, тебе не спится»).

6. Оценка: Evaluation (Оценка), Comparison (Сравнение).

Данные отношения позволяют различить оценку на основе какой-либо объективной или субъективной шкалы и оценку на основе метафорическо- 
го сравнения. Предметное отношение Evaluation апеллирует к шкале, отношение-воздействие Comparison - к метафоре. Примеры обоих отношений есть на рис. 3.

7. Переизложение или подытоживание сказанного: Restatement (Переформулировка), Summary (Резюме), Solutionhood (Решение). Restatement и Summary - отношения-воздействия, Solutionhood - предметное отношение.

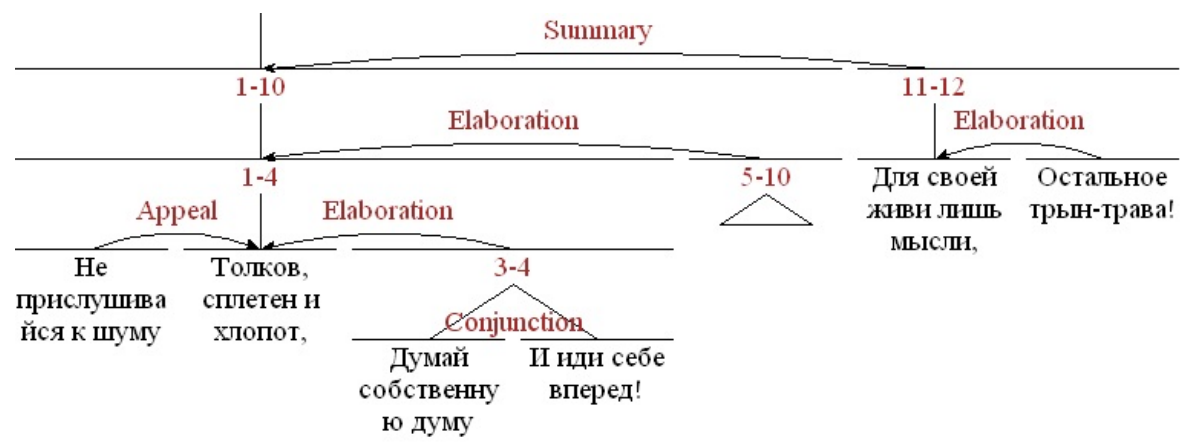

Рис. 6. Схема стихотворения А.К. Толстого «Не прислушивайся к шуму»

Изложить иначе мысли, высказанные ранее, можно по-разному. Если новое описание той же ситуации или того же рассуждения сравнимо по длине с первоначальным описанием, то используется отношение Restatement (рис. 2). Отношение Summary соответствует краткому подытоживанию высказанных ранее идей. Для данного отношения трудно подобрать легко обозримый пример, так как резюмируемая часть текста обычно весьма объёмна. На рис. 6 пример приведён в сжатом варианте, сегменты 5-10 скрыты в едином блоке.

Предметное отношение Solutionhood - это разрешение проблемной ситуации, её объяснение. Данное отношение похоже на Summary, но в отличие от него является не просто кратким переизложением, а ответом, это отношение нуждается в предварительно сформулированном проблемном вопросе. В стихотворном тексте отношение Solutionhood часто подводит итог всему рассуждению, давая ответ на вопрос, заданный в самом начале текста. В таких случаях ядро и сателлит являются сложными сегментами, их внутренняя структура выступаетчастью схемы всего текста. Например: Есть грань высокого призванья / И окончательная цель? (сателлит) / Нет, в каждом шорохе растенья / И в каждом трепете листа / Иное сльшится значенье, / Видна иная красота (ядро) (А. К. Толстой «Судя меня довольно строго»). Ещё один пример сложного сегмента, выполняющего функцию вопроса, можно увидеть на рис. 7.

8. Оставшееся предметное отношение Negation (отрицание) асимметрично, оно служит для отрицания ситуации как неосуществлённой, недопустимой или невозможной. Данное отношение является новым, оно отсутствует в стандартном списке отношений ТРС [1]. Проиллюстрируем его 
двумя примерами из стихотворений А.К. Толстого «Земля цвела» и «Одарив весьма обильно». В первом примере ситуация отрицается как не имеющая места, во втором примере она мыслится как невозможная: ...Был тихий час меж сумраком и светом, / Был лёгкий сон лесов, полей и нив; (ядро) / Не оглашал их соловей приветом (сателлит); Но чтоб падали селенья, / Чтобы нивы пустовали - (ядро) / Нам на то благословенье / Царь небесный дал едва ли! (сателлит). Здесь нет явного противопоставления ситуаций как при Contrast, Antithesis, Otherwise. Речь вообще может идти только об одной ситуации, без её сопоставления с чем-либо.

Solutionhood

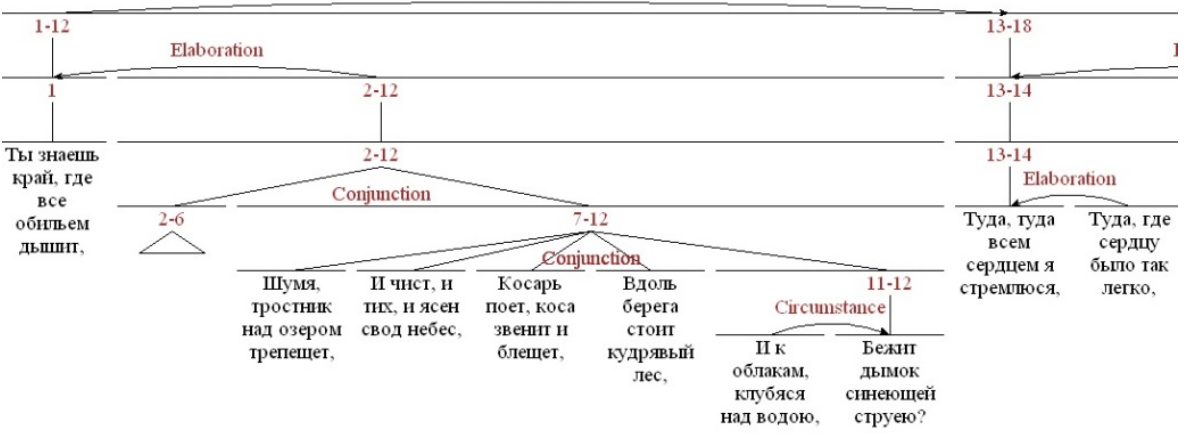

Рис. 7. Схема стихотворения А.К. Толстого «Ты знаешь край, где всё обильем дышит»

Таким образом, общее количество отношений, использованных для анализа текстов, равно 33. Из них 7 (Content, Attitude, Appeal, Warning, Promise, Directive, Negation) являются новыми. Остальные отношения входят в классический список из [1], кроме них в этом списке есть ещё несколько отношений, которые в проанализированных текстах не встретились и, соответственно, в данной статье не названы.

\section{Языковой материал}

Рассмотренные в предыдущем разделе отношения использованы для анализа стихотворных и прозаических текстов, написанных А.К. Толстым. Основным объектом исследования являются стихотворные тексты. Прозаические тексты были привлечены в меньшем объёме, они предназначались для выработки единых критериев идентификации отношений и пробного сравнительного анализа. Для исследования были выбраны только лирические стихотворения небольшого размера (минимальное количество строк 7 , максимальное 56, в среднем 20,4). Множество стихотворений разделено на три периода: 1840-1851, 1856-1859, 1862-1875. Было проведено пробное сравнение собственных стихотворений А.К. Толстого и его переводов стихотворений Г. Гейне и А. Шенье.

В качестве прозаических произведений были взяты письма А.К. Толстого к В.М. Лазаревскому, написанные в период 1857-1885 гг., а также предисловие и эпилог из «Князя Серебряного». Выбор именно этих фраг- 
ментов исторического романа А.К. Толстого обусловлен тремя причинами: 1) предисловие и эпилог представляют собой целостные тексты; 2) эти тексты сравнимы по объёму с остальными проанализированными группами текстов; 3) как и остальные рассмотренные в данном исследовании тексты, они являются монологическими. Сравнение структур, построенных на основе ТРС, для монологических и диалогических текстов, - отдельный вопрос, нуждающийся в изучении.

Использованы электронные версии текстов А.К. Толстого, находящиеся в свободном доступе на сайте проекта «Собрание классики» Lib.Ru/Классика (http://az.lib.ru/t/tolstoj_a_k/).

Основные числовые характеристики проанализированного языкового материала приведены в табл. 1. При подсчёте количества использований отношений число сегментов, вовлечённых в эти отношения, не учитывается. Например, в схеме на рис. 7 показаны три случая использования отношения Conjunction. То, что в двух из этих случаев имеется по пять конъюнктов, в подсчёте не отражено.

Таблица 1

Числовые характеристики проанализированных текстов

\begin{tabular}{|l|c|c|c|c|c|}
\hline $\begin{array}{c}\text { Периоды поэти- } \\
\text { ческого творче- } \\
\text { ства }\end{array}$ & $\begin{array}{c}\text { Количество } \\
\text { текстов }\end{array}$ & $\begin{array}{c}\text { Количество } \\
\text { словоупо- } \\
\text { треблений }\end{array}$ & $\begin{array}{c}\text { Количество } \\
\text { элементар- } \\
\text { ных сегмен- } \\
\text { тов }\end{array}$ & $\begin{array}{c}\text { Количество } \\
\text { использова- } \\
\text { ний отно- } \\
\text { шений }\end{array}$ & $\begin{array}{c}\text { Количество } \\
\text { строк в сти- } \\
\text { хотворениях }\end{array}$ \\
\hline $1840-1851$ & 10 & 1161 & 252 & 206 & 227 \\
\hline $1856-1859$ & 12 & 1095 & 217 & 180 & 211 \\
\hline $1862-1875$ & 10 & 1149 & 235 & 199 & 216 \\
\hline $\begin{array}{l}\text { Переводы поэзии } \\
1858-1868\end{array}$ & 12 & 660 & 121 & 106 & 116 \\
\hline $\begin{array}{l}\text { Письма В.М. Ла- } \\
\text { заревскому }\end{array}$ & 8 & 1100 & 173 & 158 & \\
\hline $\begin{array}{l}\text { Проза (Князь } \\
\text { Серебряный) }\end{array}$ & 2 & 820 & 126 & 119 & \\
\hline & 54 & 5985 & 1124 & 968 & 770 \\
\hline
\end{tabular}

\section{Анализ построенных схем}

Ниже представлен ряд возможностей сопоставления разных групп текстов по тем наборам отношений, которые в этих текстах используются.

Сравнительный анализ проводился для следующих типов текстов:

а) три группы стихотворений А.К. Толстого, относящиеся к разным периодам творчества (1840-1851, 1856-1859, 1862-1875);

б) собственные стихотворения А.К. Толстого (без разделения на периоды) и переводы стихотворений других авторов;

в) стихотворения А.К. Толстого (без разделения на периоды, без переводов), его письма и проза.

Исходными данными, облегчающими выявление закономерностей встречаемости отношений, являются диаграммы, одна из них приведена на рис. 8. Здесь показаны относительные частоты встречаемости отношений в 
стихотворениях трёх периодов творчества А.К. Толстого. Представлено только 28 отношений, так как оставшиеся пять из них (Joint, Directive, Promise, Otherwise, Condition) в рассмотренных стихотворных текстах не встретились. Частотность вычислялась как процент случаев использования заданного отношения от общего количества использований отношений в стихотворениях соответствующего периода.

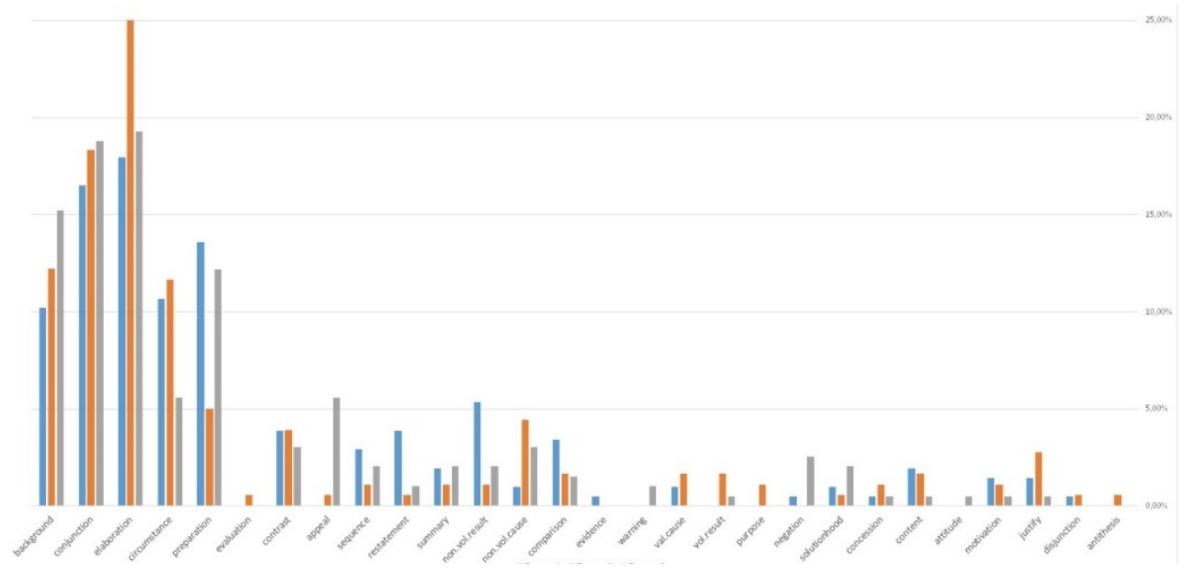

Рис. 8. Стихотворения трёх периодов творчества А.К. Толстого

На диаграмме для каждого отношения построена группа из трёх линий: они соответствуют первому, второму и третьему периодам творчества А.К. Толстого. Аналогичные диаграммы были построены и для двух других групп сравниваемых текстов. Это позволило сформировать определённые интегральные характеристики, принцип формирования которых был следующим.

Допустим, что сравниваются три множества текстов: А, В, С. Всего при построении схем было использовано 33 отношения. Из этого множества отношений выбираются три попарно не пересекающихся подмножества $\mathrm{R}_{\mathrm{A}}, \mathrm{R}_{\mathrm{B}}, \mathrm{R}_{\mathrm{C}}$. Отношение $\mathrm{R}$ включается в множество $\mathrm{R}_{\mathrm{A}}$ в том и только в том случае, если в текстах из множества А его частотность хотя бы на единицу больше, чем в каждом из двух других множеств текстов (В и С). Среди использованных при разметке 33 отношений могут оказаться такие, которые не вошли ни в одно из множеств $\mathrm{R}_{\mathrm{A}}, \mathrm{R}_{\mathrm{B}}, \mathrm{R}_{\mathrm{C}}$.

Например, при сравнении трёх периодов творчества А.К. Толстого были построены множества отношений Р1 - для периода 1840-1851, Р2 - для периода 1856-1859, Р3 - для периода 1862-1875 гг. Отношение Background было включено в множество Р3, так как в текстах этого периода его частотность больше, чем в каждом из текстов двух других периодов (15 против 10 и $12 \%$ соответственно). Отношение Summary не вошло ни в одно из множеств P1, Р2, Р3, так как частотность его встречаемости в текстах третьего периода лишь незначительно превышает его частотность в текстах каждого из остальных двух периодов. 
При сравнении стихотворений трёх периодов творчества А.К. Толстого были сформированы следующие интегральные характеристики:

P1: Preparation, Restatement, Non-volitional result, Comparison

P2: Elaboration, Circumstance, Non-volitional cause, Volitional result, Purpose, Justify

P3: Background, Appeal, Warning, Negation, Solutionhood

Содержательное рассмотрение этих характеристик позволяет интерпретировать различия между тремя группами текстов следующим образом. Характеристика Р1 отражает скорее созерцательное отношение наблюдателя к не зависящему от него состоянию дел. Для первого периода наиболее характерны разрывы синтаксических связей (Preparation). Характеристика же Р2 свидетельствует об увеличении детализации событий, появлении целеполагания и суждений на основе опыта (Justify). Сравнение трёх интегральных характеристик наибольшее разнообразие отношений выявило во втором периоде. Представляет интерес характеристика Р3: она отражает повышение риторических обращений (с позитивным или негативным призывом) к внешним силам, подытоживание и решение проблемных ситуаций (Solutionhood). Компонент отрицания или неприятия ситуации имеется в отношениях Otherwise, Antithesis и Warning, в чистом виде он представлен в Negation.Характеристика Р3 включает Warning и Negation, Множества P1 и P2 не содержат отношений с таким компонентом. То есть в третьем периоде восприятие мира более контрастно, включает суждения о существующем и о несуществующем. Стоит обратить внимание также на те отношения, которые не попали ни в одну характеристику из-за того, что являются частотными для всех трёх периодов. Таковы прежде всего отношение Conjunction, а также отношения Contrast и Summary. На данном этапе работы нельзя сказать, характерны ли эти отношения для данного автора или вообще для поэзии.

При сравнении собственных стихотворений А. К. Толстого и переводов стихотворений других авторов были сформированы две интегральные характеристики (соответственно Р4 и Р5):

P4: Elaboration, Circumstance, Preparation, Non-volitional result, Conjunction, Comparison, Justify

P5: Background, Appeal, Volitional cause, Concession, Content, Otherwise

Меньшее количество отношений в Р5, возможно, объясняется тем, что объём рассмотренных переводов меньше объёма проанализированных стихотворений самого А.К. Толстого. При сравнении полученных интегральных характеристик можно заметить, что в первой из них преобладает неволитивность, во второй - волитивность. Отношение Conjunction частотно во всех рассмотренных стихотворных текстах, однако в текстах А.К. Толстого эта оценка оказалась выше. Для переводов в большей степени характерно обращение в ходе рассуждения к нежелательным ситуациям (Otherwise) или к мнимым препятствиям (Concession). Детализированность рассуждений и разрывы синтаксических связей в большей степени присущи текстам А.К. Толстого, чем переводам. 
При сравнении стихотворений А.К. Толстого, его писем и прозы были сформированы следующие три интегральные характеристики (соответственно Р6, Р7, Р8):

P6: Conjunction, Restatement, Non-volitional Result, Solutionhood

P7: Contrast, Evidence, Attitude, Motivation, Justify, Joint, Disjunction, Promise, Directive

P8: Non-volitional Cause, Comparison, Volitional cause, Negation

Данное сопоставление свидетельствует о том, что отношение Conjunction более характерно для стихотворных текстов, чем для прозы. В этом типе текстов также частотны переизложение мысли (Restatement) и нахождение решения (Solutionhood). Как можно было ожидать заранее, речевые акты наиболее частотны в текстах писем. Здесь же проявились все три вида убеждения: на основе фактов (Evidence), личного опыта (Justify), апелляция к интересам адресата (Motivation).

В табл. 2 указана суммарная частотность интегральных характеристик для сравниваемых групп текстов. Числовые значения вычислялись как процент использования отношений из рассматриваемой интегральной характеристики от общего числа использований отношений в соответствующем множестве текстов. Полужирным шрифтом выделены значения, являющиеся максимальными для сравниваемой группы.

Таблица 2

Частотность интегральных характеристик

\begin{tabular}{|l|c|c|c|c|c|c|c|c|}
\hline Группы текстов & P1 & P2 & P3 & P4 & P5 & P6 & P7 & P8 \\
\hline Период 1 & $\mathbf{2 6 , 2}$ & 31,1 & 11,7 & & & & & \\
\hline Период 2 & 8,3 & $\mathbf{4 6 , 7}$ & 13,3 & & & & & \\
\hline Период 3 & 16,8 & 28,9 & $\mathbf{2 6 , 4}$ & & & & & \\
\hline Все периоды & & & & 17,7 & $\mathbf{6 4 , 8}$ & & & \\
\hline Переводы & & & & $\mathbf{4 0 , 2}$ & 43,1 & & & \\
\hline Все периоды & & & & & & 7,7 & 6,9 & $\mathbf{4 0 , 5}$ \\
\hline Письма & & & & & & $\mathbf{3 3 , 5}$ & 1,9 & 18,4 \\
\hline Проза & & & & & & 12,6 & $\mathbf{1 6 , 8}$ & 23,5 \\
\hline
\end{tabular}

Помимо интегральных характеристик P1-P8 можно усмотреть и другие закономерности. Так, по построенным диаграммам видно, что отношения Concession и Volitional cause редки в стихотворных текстах А.К. Толстого (0,7 и 0,9 соответственно), но более частотны в прозе $(4,2$ и 6,7) и письмах $(4,6$ и 5,3). В прозе и поэзии А.К. Толстого почти одинаково частотны отношения Circumstance $(9,2$ и 9,3), для писем эта оценка ниже $(3,3)$. Можно также заметить, что в стихотворных текстах отношение Appeal, как правило, сопряжено с одним из отношений Solutionhood или Summary, реже - с Restatement, т.e. риторический призыв Appeal привлекает внимание к определённой проблеме, которая затем резюмируется, получает решение или переформулируется. Такая закономерность наблюдается во всех случаях использования Appeal в стихотворениях третьего периода творчества А.К. Толстого, но только в половине случаев использования Appeal в переводах стихотворений А. Шенье и 
Г. Гейне. Кроме того, резюме (Summary), решение (Solutionhood), переформулирование (Restatement) обычно представлены сложным сегментом, включающим ещё одно вхождение отношения Appeal. Такая ритмичность структуры характерна для третьего, самого позднего, периода поэтического творчества А.К. Толстого.

Conjunction, Restatement, Sequence - потенциально ритмичные структуры. В принципе таково же и отношение Disjunction, но в рассмотренных стихотворных текстах оно почти не используется. Отношение Conjunction, напротив, для этих текстов очень характерно, причём часто встречается в осложнённых вариантах, например во вложенных конъюнкциях (рис. 4) и конъюнкциях со сложными конъюнктами (рис. 5), более сложный конъюнкт чаще расположен последним.

\section{Заключение}

В результате разметки посредством инструмента RSTTool был построен корпус схем ТРС. Каждая схема изображает ход гетерогенного познавательного процесса, воплощённого в тексте и подлежащего реконструкции при понимании этого текста. Сопоставление схем трактуется как сопоставление соответствующих познавательных процессов. На основе выявления особенностей схем для нескольких групп текстов продемонстрирована возможность формирования интегральных характеристик, присущих этим группам текстов.

Отдельным результатом проделанной работы является разработка принципов построения схем ТРС для стихотворного текста и правил идентификации отношений. Имеющиеся исследования на основе ТРС, как правило, ориентированы на поиск текстовых индикаторов отношений. В случае стихотворных текстов такие индикаторы редки и надёжность их невелика. Поэтому основное внимание было уделено тем правилам идентификации отношений, которые относятся к сфере содержания, в частности с привлечением возможностей синонимической трансформации и построения логической формы.

Построенное множество схем и результаты его анализа могут быть использованы для сопоставления текстов разных типов, анализа условий встречаемости отношений, выявления закономерностей комбинирования отношений, изучения и моделирования стилей рассуждения, исследования авторских стилей, решения задач моделирования рассуждений в сфере искусственного интеллекта. Кроме того, выявляемые на данном корпусе закономерности могут использоваться в рамках традиционных филологических исследований при изучении творчества А.К. Толстого.

В заключение хочется отметить, что, как это ни парадоксально, расстановка риторических отношений и построение схем не разрушает общего впечатления от поэтического произведения, a, скорее, наоборот, вынуждает погрузиться в его смысл и задуматься о той реальности, о которой размышляет поэт, в конечном итоге приводя к более глубокому пониманию 
текста. Возможно, это служит ещё одним подтверждением мысли Ю.М. Лотмана и Р. Познера, о которой говорилось в начале статьи. Семиотическое новаторство, присущее стихотворному тексту, делает форму и содержание трудноразделимыми, так как содержание отчасти запечатлено в форме, в частности в форме мысли. Поэтому углублённое внимание к форме мысли позволяет лучше понять содержание.

\section{Лuтература}

1. Mann W., Thompson S. Rhetorical Structure Theory: A Theory of Text Organization. Technical report No. ISI/RS-87-190. University of Southern California, Information Science Institute, 1987. 91 p. URL: https://www.sfu.ca/rst/pdfs/Mann_Thompson_1987.pdf (date of access: 10.08.2020).

2. O'Donnell M. RST-Tool: An RST Analysis Tool. // Proceedings of the 6th European Workshop on Natural Language Generation March 24-26, 1997 Gerhard-Mercator University. Duisburg, Germany, 1997. P. 92-96.

3. Рассказы о сновидениях: Корпусное исследование устного русского дискурса / под ред. А.А. Кибрика, В.И. Подлесской. М. : Языки славянских культур, 2009. 736 с.

4. Taboada M., Mann W. Rhetorical Structure Theory: Looking back and moving ahead // Discourse Studies. SAGE Publications, 2006. Vol. 8, № 3. P. 423-459.

5. Лотман Ю.М. Анализ поэтического текста: Структура стиха. Л. : Просвещение, 1972. $272 \mathrm{c}$.

6. Гаспаров М.Л. Метр и смысл. М. : Фортуна ЭЛ, 2012. 416 с.

7. Мартыненко Г.Я. Основы стилеметрии. Л. : Изд-во Ленингр. ун-та, 1988. 176 с.

8. Rühlemann C., Aijmer R. Corpus Pragmatics: Laying the Foundations // Corpus pragmatics: a handbook Karin Aijmer / ed. by Christoph Rühlemann. Cambridge University Press, 2014. $480 \mathrm{p}$.

9. Mann W., Thompson S. Relational Propositions in Discourse // Discourse Processes. Taylor and Francis Ltd. 1986. Vol. 9, № 1. P. 57-90.

10. Shannon C.E., Weaver W. The Mathematical Theory of Communication. The University of Illinois Press, 1949. 117 p.

11. Grice H.P. Logic and Conversation. In: Syntax and Semantics / eds. by Peter Cole, Jerry L. Morgan. New York : Academic Press, 1975. Vol. 3. P. 41-58.

12. Sperber D., Wilson D. Relevance: Communication and Cognition. Blackwell : Oxford and Harvard University Press, 1986. p. VIII +279.

13. Познер Р. Рациональный дискурс и поэтическая коммуникация: методы лингвистического, литературного и философского анализа / науч. ред. И.П. Кужелева-Саган ; пер. с англ. С.С. Носовой. Томск : Издательский Дом Томского государственного университета ; Дизайн-студия «Провинция», 2015. 296 с.

14. Koj L. Zasada przezroczystosci a antynomie semantyczne // Studia Logica. 1963. 14. S. 227-253. (In Polish).

15. Taboada M., Mann W. Applications of Rhetorical Structure Theory // Discourse Studies. SAGE Publications, 2006. Vol. 8, № 4. P. 567-588.

16. Alexander $M$. Rhetorical Structure and Reader Manipulation in Agatha Christie's Murder on the Orient Express // Miscelanea: A Journal of English and American Philology. University of Zaragoza. 2009. Vol. 39. P. 13-27.

17. Lu Y. A Discourse Analysis of Zhuang Dialogue Folk Songs. A thesis submitted in partial fulfillment of the requirements for the degree of Master of Arts (linguistics) faculty of graduate studies. Mahidol University, 2016. $183 \mathrm{p}$.

18. Тимофеева М.К. Опыт использования теории риторической структуры для представления логико-когнитивной организации поэтического текста // Вестник НГУ. Серия: Лингвистика и межкультурная коммуникация. 2020. Т. 18, № 2. С. 28-45. 
19. Chistova E., Kobozeva M., Pisarevskaya D., Shelmanov A., Smirnov I., Toldova S. Towards the Data-Driven System for Rhetorical Parsing of Russian Texts // Proceedings of Discourse Relation Parsing and Treebanking. DISRPT2019, Minneapolis, MN, June 6, 2019. P. 82-87.

20. Бакиева А.М., Батура Т.В. Исследование применимости теории риторических структур для автоматической обработки научно-технических текстов // Cloud of Science, 2017. T. 4, № 3. C. 450-464.

21. Das D., Taboada M. Multiple Signals of Coherence Relations // Discours [Online], 24 | 2019, Online since 30 October 2019, connection on 30 October 2019. URL: http:// journals.openedition.org/discours/10032 (date of access: 10.08.2020).

22. Taboada M. Implicit and Explicit Coherence Relations. In J.Renkema (ed.). Discourse, of Course. An overview of research in discourse studies. Amsterdam : John Benjamins, 2009. P. 125-138.

23. Potter A. Reasoning between the Lines: A Logic of Relational Propositions. Dialogue and Discourse // US: The Dialogue \& Discourse Board of Editors. 2019. Vol. 9, № 2. P. 80110.

\section{The Rhetorical Structure Theory as an Instrument for Analyzing Poetic Texts}

Vestnik Tomskogo gosudarstvennogo universiteta. Filologiya - Tomsk State University Journal of Philology. 2020. 68. 109-137. DOI: 10.17223/19986645/68/6

Mariya K. Timofeeva, Federal Research Center for Informational and Computational Technologies (Novosibirsk, Russian Federation); Sobolev Institute of Mathematics of the Siberian Branch of the Russian Academy of Sciences (Novosibirsk, Russian Federation). E-mail: mtimof@inbox.ru

Keywords: rhetorical relations, relational propositions, cognitive structure, poetic texts, text coherence, Aleksey K. Tolstoy

The study is supported by the Russian Science Foundation, Project No. 19-18-00466.

The article presents the results of applying the Rhetorical Structure Theory (RST) to poetic texts written in Russian. A poetic text is treated as a specific cognitive process. The work aims to reconstruct the structure of hypothetical cognitive steps that underlie the process of understanding a text and depend on implicit relational propositions that make the text coherent. The analyzed language material consists of the poetic texts written by Aleksey K. Tolstoy, the fragments from his prosaic texts, his letters, and his translations of poetic texts written by other authors. Three stages of investigation are discussed. The first and basic one is methodological; it consists in elaborating the principles of applying RST to poetic texts, particularly, in defining the rules of segmentation, in building the set of relations, and in developing the rules of identifying these relations in context. Seven types of relations were added to the ordinary set of relations presupposed by RST. Poetic texts rarely include reliable textual indicators of relations; therefore, these rules bring in focus semantic, pragmatic, and logical aspects of text understanding. The methodological stage was iterative and included several recalibrations; the summarizing principles are the result of adaptation the procedure to all sorts of the texts under consideration. The second stage of the investigation realizes these principles in the process of analyzing several types of texts by the means of RST. This stage results in a set of schemas. Finally, the third stage is devoted to a comparative analysis of the schemas corresponding to different groups of texts. The comparison goes along the following lines: 1) three periods of Tolstoy's poetic writing: the early period 1840-1851, the middle period $1856-1859$, and the late period $1862-1875 ; 2$ ) the lyrics written by Tolstoy against his translations of poetic texts written by other poets; 3 ) Tolstoy's poetry against his prose and letters. After observing the percentage of relations in the corresponding sets of schemas, eight integral characteristics were formed. Each of them summarizes the relations that reach their maximum for one of the groups under consideration. For instance, each of the three periods of Tolstoy's poetic writing received its own integral characteristic, and these data allow discuss- 
ing specific trends in cognitive processes reflected by the corresponding texts. Along with the integral characteristics, several other peculiarities of the groups of texts were shaped.

\section{References}

1. Mann, W. \& Thompson, S. (1987) Rhetorical Structure Theory: A Theory of Text Organization. Technical report No. ISI/RS-87-190. University of Southern California, Information Science Institute. [Online] Available from: https://www.sfu.ca/rst/ pdfs/Mann_Thompson_1987.pdf. (Accessed: 10.08.2020).

2. O'Donnell, M. (1997) RST-Tool: An RST Analysis Tool. Proceedings of the 6th European Workshop on Natural Language Generation. 24-26 March 1997. Gerhard-Mercator University. Duisburg, Germany. pp. 92-96.

3. Kibrik, A.A. \& Podlesskaay, V.I. (eds) (2009) Rasskazy o snovideniyakh: Korpusnoe issledovanie ustnogo russkogo diskursa [Stories about Dreams: A Corpus Study of Russian Oral Discourse]. Moscow: Yazyki slavyanskikh kul'tur.

4. Taboada, M. \& Mann, W. (2006) Rhetorical Structure Theory: Looking back and moving ahead. Discourse Studies. 8 (3). pp. 423-459.

5. Lotman, Yu.M. (1972) Analiz poeticheskogo teksta. Struktura stikha [Analysis of the poetic text. The structure of the verse]. Leningrad: Prosveshchenie.

6. Gasparov, M.L. (2012) Metr i smysl [Meter and meaning]. Moscow: Fortuna EL.

7. Martynenko, G.Ya. (1988) Osnovy stilemetrii [Basics of stylometry]. Leningrad: Leningrad State University.

8. Rühlemann, C. \& Aijmer, R. (2014) Corpus Pragmatics: Laying the Foundations. In: Aijmer, K. \& Rühlemann, C. (eds) Corpus pragmatics: a handbook. Cambridge University Press.

9. Mann, W. \& Thompson, S. (1986) Relational Propositions in Discourse. Discourse Processes. 9 (1). pp. 57-90.

10. Shannon, C.E. \& Weaver, W. (1949) The Mathematical Theory of Communication. Urbana, Illinois: The University of Illinois Press.

11. Grice, H.P. (1975) Logic and Conversation. In: Cole, P. \& Morgan, J.L. (eds) Syntax and Semantics. Vol. 3. New York: Academic Press. pp. 41-58.

12. Sperber, D. \& Wilson, D. (1986) Relevance: Communication and Cognition. Blackwell, Oxford and Harvard University Press.

13. Pozner, R. (2015) Ratsional'nyy diskurs i poeticheskaya kommunikatsiya: metody lingvisticheskogo, literaturnogo $i$ filosofskogo analiza [Rational discourse and poetic communication: methods of linguistic, literary and philosophical analysis]. Translated from English by S.S. Nosova. Tomsk: Tomsk State University; Dizayn-studiya "Provintsiya".

14. Koj, L. (1963) Zasada przezroczystosci a antynomie semantyczne. Studia Logica. V.XIV. pp. 227-253. (In Polish).

15. Taboada, M. \& Mann, W. (2006) Applications of Rhetorical Structure Theory. Discourse Studies. 8 (4). pp. 567-588.

16. Alexander, M. (2009) Rhetorical Structure and Reader Manipulation in Agatha Christie's Murder on the Orient Express. Miscelanea: A Journal of English and American Philology. 39. pp. 13-27.

17. Lu, Y. (2016) A Discourse Analysis of Zhuang Dialogue Folk Songs. A thesis submitted in partial fulfillment of the requirements for the degree of Master of Arts (linguistics) faculty of graduate studies. Mahidol University.

18. Timofeeva, M.K. (2020) Applicability of Rhetorical Structure Theory for Representing Logical-Cognitive Organization of Poetic Texts: Empirical Investigation. Vestnik NGU. Seriya: Lingvistika i mezhkul'turnaya kommunikatsiya - NSU Vestnik. Series: Linguistics and Intercultural Communication. 18 (2). pp. 28-45. (In Russian). DOI: 10.25205/1818-7935-2020-18-2-28-45 
19. Chistova, E. et al. (2019) Towards the Data-Driven System for Rhetorical Parsing of Russian Texts. Proceedings of Discourse Relation Parsing and Treebanking. DISRPT2019. June 6, 2019. Minneapolis, MN. pp. 82-87.

20. Bakieva, A.M. \& Batura, T.V. (2017) Research of Applicability of the Rhetorical Structure Theory for Automatic Processing of Scientific and Technical Texts. Cloud of Science. 4 (3). pp. 450-464. (In Russian).

21. Das, D. \& Taboada, M. (2019) Multiple Signals of Coherence Relations. Discours. 30 October 2019. [Online] Available from: http://journals.openedition.org/discours/10032. (Accessed: 10.08.2020).

22. Taboada, M. (2009) Implicit and Explicit Coherence Relations. In: Renkema, J. (ed.). Discourse, of Course. An overview of research in discourse studies. Amsterdam: John Benjamins. pp. 125-138.

23. Potter, A. (2019) Reasoning between the Lines: A Logic of Relational Propositions. Dialogue and Discourse. 9 (2). pp. 80-110. 